\title{
Влияние холецистэктомии
}

\section{в молодом возрасте на течение метаболического синдрома}

\section{у женщин}

\section{Лебедева О.В. • Буеверов А.О.' • Буеверова Е.Л. • Никитина Л.О. ${ }^{2}$}

Лебедева Ольга Валерьевна -

аспирант кафедры медико-

социальной экспертизы, неотложной

и поликлинической терапии института

профессионального образования

$\bowtie 115580$, г. Москва, ул. Кустанайская,

2/1-41, Российская Федерация.

Тел.: +7 (916) 9890595.

E-mail: ovgastro@mail.ru

Буеверов Алексей Олегович - д-р мед. наук, профессор кафедры медикосоциальной экспертизы, неотложной и поликлинической терапии института профессионального образования'

Буеверова Елена Леонидовна -

канд. мед. наук, ассистент кафедры пропедевтики внутренних болезней лечебного факультета'

Никитина Лилиана Олеговна канд. мед. наук, проректор по постдипломному и дополнительному образованию ${ }^{2}$

1 ФГАОУ ВО «Первый Московский государственный медицинский университет им. И.М. Сеченова» Минздрава России; 119991, г. Москва, ул. Трубецкая, 8/2,

Российская Федерация

${ }^{2}$ ФГБУ «Национальный медицинский исследовательский центр реабилитации и курортологии» Минздрава России; 121099, г. Москва, ул. Новый Арбат, 32, Российская Федерация
Актуальность. Сегодня в фокусе внимания исследователей находятся такие проблемы, как метаболический синдром и процессы формирования неалкогольной жировой болезни печени, выявление факторов, влияющих на скорость развития дистрофических и фибротических изменений в ткани печени. Настоящее исследование демонстрирует попытку более детального изучения метаболических нарушений и состояния ткани печени в постхолецистэктомическом периоде у пациентов с изначально регистрируемым метаболическим синдромом. Цель - изучить влияние холецистэктомии в молодом возрасте на течение метаболического синдрома у женщин. Материал и методы. Проведено ретроспективное аналитическое исследование. В выборку включены 57 пациенток с признаками метаболического синдрома (критерии IDF 2005 г.) в возрасте от 18 до 44 лет (молодой возраст согласно определению Всемирной организации здравоохранения). Из них 27 пациенток, страдающих желчнокаменной болезнью, составили основную группу, 30 пациенток, перенесших холецистэктомию в этот возрастной промежуток, вошли в группу сравнения. Проанализированы данные анамнеза, клинического обследования, лабораторные показатели, данные ультразвукового исследования органов брюшной полости, эзофагогастродуоденоскопии, водородного дыхательного теста с лактулозой, а также результаты пункционной биопсии печени. Результаты. Неалкогольный стеатогепатит в постхолецистэктомическом периоде ассоциирован с избыточным бактериальным ростом в тонкой кишке $(p=0,026)$, ультразвуковыми признаками холангита $(p=0,041)$, синдромом диареи ( $p=0,027)$. Фиброз статистически значимо чаще регистрировался в сочетании с хронической диареей $(p=0,034)$ и клиническими проявлениями постхолецистэктомического синдрома в анамнезе $(p=0,044)$. Выявлена сильная прямая корреляционная связь между степенью фиброза и длительностью постхолецистэктомического периода ( $r=0,77 ; p=0,047)$. Заключение. Холецистэктомия в молодом возрасте является предиктором прогрессирования метаболических расстройств у женщин с метаболическим синдромом.

Ключевые слова: желчнокаменная болезнь, метаболический синдром, холецистэктомия, неалкогольная жировая дистрофия печени

Для цитирования: Лебедева $\mathrm{OB}$, Буеверов $\mathrm{AO}$, Буеверова ЕЛ, Никитина ЛО. Влияние холецистэктомии в молодом возрасте на течение метаболического синдрома у женщин. Альманах клинической медицины. 2017;45(5):384-91. doi: 10.18786/20720505-2017-45-5-384-391

Поступила 29.05.2017; принята к публикации 01.08 .2017 
M етаболический синдром и неалкогольная жировая болезнь печени (НАЖБП) как его компонент - одна из наиболее обсуждаемых в научном сообществе тем. Учитывая высокую частоту выявления желчнокаменной болезни (ЖКБ) на фоне НАЖБП и большую долю больных, подвергаемых холецистэктомии в этой группе, представляется необходимым изучение состояния печени и, соответственно, метаболического статуса в постхолецистэктомическом периоде.

В течение последних 10 лет проведен целый ряд исследований, посвященных этой проблеме. Так, в 2014, 2016 и 2017 гг. опубликованы результаты масштабных исследований, выполненных на азиатской популяции (суммарно выборка составила более 55000 респондентов). Было установлено наличие статистически значимой ассоциации холецистэктомии и прогрессирования метаболического синдрома, а также взаимосвязи холецистэктомии и НАЖБП. Однако эти работы выполнены на основе сонографической верификации НАЖБП, без учета этиологии ЖКБ, метаболического статуса пациента до холецистэктомии, возраста исследуемых и их гендерной принадлежности. Дополнительная корректировка данных с включением в анализ инсулинорезистентности и других известных факторов, ассоциированных с развитием НАЖБП, не изменила результаты вышеуказанных исследований. Пилотное исследование чилийских авторов 2017 г., в котором изучена динамика метаболических изменений в постхолецистэктомическом периоде у пациентов без проявлений ожирения до холецистэктомии, подтвердило негативное влияние оперативного лечения в аналогичном ключе [1-4].

Анализ данных литературы показывает, что сочетание ЖКБ и НАЖБП имеет следующие особенности: у 55\% пациентов с ЖКБ наблюдаются морфологические признаки НАЖБП, у $10 \%$ пациентов с ЖКБ отмечены выраженные фибротические изменения печени, а 19,8\% пациентов с НАЖБП страдают ЖКБ [5]. Более того, в общей популяции ЖКБ встречается у $13 \%$, а в популяции с НАЖБП частота выявления ЖКБ достигает $34,3 \%$. В популяции после холецистэктомии распространенность НАЖБП максимальна - 48,4\% [6]. Четкой патогенетической связи между ЖКБ и НАЖБП не установлено, хотя известные этиологические и патогенетические механизмы этих заболеваний схожи. Общим патогенетическим звеном признана инсулинорезистентность и ее эффекты на органы желудочно-кишечного тракта, метаболизм углеводов и липидов.

Цель настоящего исследования - изучить влияние холецистэктомии в молодом возрасте на течение метаболического синдрома у женщин.

Этическое утверждение. Исследование одобрено локальным комитетом по этике ФГАОУ ВО Первый МГМУ им. И.М. Сеченова Минздрава России, протокол № 05-13 от 15.05.2013. Все пациенты подписали информированное добровольное согласие на проведение исследований и вмешательств в рамках исполнения статьи 20 Федерального закона от 21.11.2011 № 323-Ф3 «Об основах охраны здоровья граждан в Российской Федерации».

\section{Материал и методы}

В исследование включены 57 женщин с признаками метаболического синдрома в возрасте от 18 до 44 лет, страдающих ЖКБ либо перенесших холецистэктомию в этот же возрастной промежуток. Пациенты разделены на две группы: основную составили 27 больных с ЖКБ, группу сравнения 30 пациенток после холецистэктомии. Наличие метаболического синдрома регистрировалось согласно критериям Международной федерации диабета (International Diabetes Federation - IDF) 2005 г.

Набор пациентов осуществлялся по факту их обращения на амбулаторный прием гастроэнтерологического и терапевтического профиля в консультативно-диагностический центр ФГБУ «Федеральный научно-клинический центр специализированных видов медицинской помощи и медицинских технологий ФМБА России». Исследование ограничено женской популяцией, так как в общей выборке среди мужской части пациентов ЖКБ в молодом возрасте зарегистрирована всего в 22 случаях (1,2\% от общей выборки), а признаки метаболического синдрома выявлены только у $5(0,41 \%)$ пациентов, что недостаточно для формирования полноценной группы наблюдения.

Критериями включения в исследование были наличие ультразвуковых признаков жирового перерождения печени при сонографии, наличие ЖКБ согласно данным ультразвукового исследования (УЗИ), компьютерной или магнитно-резонансной томографии, рентгенографии; возраст пациента от 18 до 44 лет на момент манифестации заболевания или выполнения холецистэктомии, наличие у пациента медицинской документации, позволяющей оценить характер течения болезни. 
Критериями исключения служили возраст старше 44 лет на момент диагностики ЖКБ, злоупотребление алкоголем по данным опросника, наличие в анамнезе хронических вирусных гепатитов или другой патологии печени за исключением НАЖБП, тяжелые сопутствующие заболевания других органов и систем, прием респондентами лекарственных препаратов, обладающих зарегистрированным протекторным либо иным воздействием на печень.

Использовали следующие методы исследования:

- изучение анамнеза жизни и болезни, изучение алкогольного анамнеза с помощью опросника AUDIT;

- осмотр, направленный на выявление клинических признаков метаболического синдрома;

- лабораторные исследования крови, подтверждающие наличие метаболического синдрома: уровень глюкозы в венозной крови натощак, инсулина натощак, определение НОМА-индекса;

- биохимический анализ сыворотки крови с оценкой показателей, отражающих выраженность воспалительного процесса и функциональное состояние печени: активность аспарагиновой (АСТ) и аланиновой (АЛТ) аминотрансфераз, гамма-глютамилтранспептидазы, щелочной фосфатазы, уровень общего и конъюгированного билирубина, белковых фракций, альбумина, протромбина; исследование крови на наличие маркеров персистенции вирусов гепатитов В и С;

- УЗИ брюшной полости, эзофагогастродуоденоскопия, дыхательный водородный тест для подтверждения синдрома избыточного бактериального роста (СИБР) (с помощью аппарата "Gastro + Gastrolyser", Bedfont, Великобритания);

- пункционная биопсия печени под контролем сонографии, окраска препаратов гематоксилином и эозином, а также окраска по Клацкину, исследование пункционного материала.

Систематизация и статистическая обработка данных проводились с помощью программного пакета Statistica, v. 10. Применялись параметрические и непараметрические статистические методы. Для выявления связей между различными показателями проводили корреляционный анализ с вычислением коэффициента корреляции и оценкой его достоверности. За уровень достоверности статистических показателей принято $\mathrm{p}<0,05$.

\section{Результаты}

Как видно из данных табл. 1, по ключевым показателям группы исследования были сопоставимы. Нарушения углеводного обмена в группе сравнения были представлены следующими вариантами: сахарный диабет 2-го типа диагностирован у 5 (5,43\%) респондентов, нарушение толерантности к глюкозе - у 3 (3,3\%), транзиторная гипергликемия - у 7 (7,6\%), гипергликемия натощак - у 5 (5,45\%) пациентов. В основной группе повышение базального уровня инсулина выявлено в 13 (14,1\%) случаях. Из них 10 пациентов были с ожирением и нарушением толерантности к глюкозе, 3 - с зарегистрированным инсулиннезависимым сахарным диабетом 2-го типа. Максимальное значение индекса НОМА - 5,5 отмечено у больных сахарным диабетом 2-го типа (больные, получавшие препараты с эффектом стимуляции выделения инсулина, не учитывались), минимальное значение в основной группе составило 2,87. В группе сравнения обнаружена прямая корреляция средней силы между уровнем холестерина $(\mathrm{r}=0,41 ; \mathrm{p}<0,028)$ и глюкозы $(\mathrm{r}=0,44$; $\mathrm{p}<0,032)$ с длительностью постхолецистэктомического периода.

Таблица 1. Характеристика исследуемых групп

\begin{tabular}{|c|c|c|c|}
\hline Параметр & $M C+$ ЖКБ, $\mathrm{n}=27$ & $\begin{array}{l}\text { MC + холецистэктомия, } \\
\mathrm{n}=30\end{array}$ & Значение $p$ \\
\hline Возраст, годы & $37,2 \pm 10,2$ & $39,3 \pm 11,1$ & 0,068 \\
\hline Poct, cM & $169 \pm 7$ & $167 \pm 7,2$ & 0,17 \\
\hline Масса тела, кг & $99,8 \pm 11,6$ & $96,5 \pm 11,9$ & 0,063 \\
\hline Индекс массы тела (кг/м²) & $43,6 \pm 0,9$ & $42,6 \pm 0,5$ & 0,074 \\
\hline Инсулин, мкМЕ/мл & $15 \pm 2,7$ & $14,3 \pm 3,5$ & 0,76 \\
\hline HOMA-IR & $4 \pm 1,2$ & $4,3 \pm 0,9^{*}$ & 0,047 \\
\hline Гиперинсулинемия, абс. (\%) & $13(48,1)^{*}$ & $5(16,6)$ & 0,002 \\
\hline †Активность АЛТ, абс. (\%) & $3(11,1)$ & $18(60)^{*}$ & 0,002 \\
\hline †Активность АСТ, абс. (\%) & $3(11,1)$ & $16(53,3)^{*}$ & 0,001 \\
\hline †Активность ГгтП (\%) & 0 & $9(30)^{*}$ & 0,006 \\
\hline Глюкоза, ммоль/л & $5,5 \pm 1,2$ & $6,06^{*}$ & 0,034 \\
\hline $\begin{array}{l}\text { Гиперхолестеринемия, } \\
\text { \% / сред. }\end{array}$ & $10 / 6,4 \pm 0,8$ & $10 / 5,9 \pm 0,9$ & $0,28 / 0,17$ \\
\hline
\end{tabular}

МС - метаболический синдром, ЖКБ - желчнокаменная болезнь, АЛТ - аланиновая аминотрансфераза, АСТ - аспарагиновая аминотрансфераза, ГГТП - гамма-глютамилтранспептидаза, $\uparrow$ - повышенная активность

"Межгрупповые различия достигли уровня статистической значимости 
При изучении результатов инструментальных методов исследования выявлено статистически значимое превалирование эндоскопической картины гастроэзофагеальной рефлюксной болезни в группе холецистэктомированных больных: $4(14,8 \%)$ случая в основной и $15(50 \%)$ в группе сравнения (табл. 2). Аналогичное распределение данных наблюдалось и при анализе результатов водородного дыхательного теста, проводимого с целью регистрации СИБР в тонкой кишке, $16(59,2 \%)$ и $29(96,6 \%)$ наблюдений соответственно. При УЗИ органов брюшной полости также отмечена более высокая частота встречаемости картины холангита в группе сравнения - 13 (43,3\%) случаев против $5(18,5 \%)$ в основной группе.

Анализ данных гистологического исследования ткани печени показал большее количество случаев белковой дегенерации гепатоцитов в группе сравнения (табл. 3). Выявлена ассоциация гистологической активности гепатита в постхолецистэктомическом периоде с регистрацией СИБР в тонкой кишке $(\mathrm{p}=0,026)$, а также длительностью постхолецистэктомического периода $(\mathrm{r}=0,32 ; \mathrm{p}<0,05)$. Активный гепатит также статистически значимо чаще регистрировался у пациентов с ультразвуковыми проявлениями холангита $(\mathrm{p}=0,041)$ и синдромом хронической диареи $(\mathrm{p}=0,027)$. У пациенток с метаболическим синдромом в постхолецистэктомическом периоде отмечено более раннее выявление фиброза печени относительно естественного течения НАЖБП (средняя длительность постхолецистэктомиче-

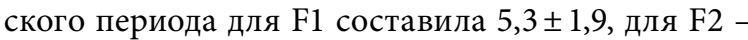
$7,3 \pm 1,6$ года; $\mathrm{p}=0,32)$. Фибротические изменения значимо чаще регистрировали в сочетании с хронической диареей $(\mathrm{p}=0,034)$ и клиническими проявлениями постхолецистэктомического синдрома в анамнезе $(\mathrm{p}=0,044)$. Обнаружена прямая сильная корреляционная связь между степенью тяжести фибротических изменений и длительностью постхолецистэктомического периода $(\mathrm{r}=0,77 ; \mathrm{p}=0,047)$.

\section{Обсуждение}

При анализе полученных данных выявлено прогрессирование метаболических расстройств в группе сравнения. Повышение частоты гипергликемии натощак и снижение частоты регистрации базальной гиперинсулинемии можно расценивать как результат истощения $\beta$-клеток поджелудочной железы и нарушения регуляции секреции инсулина. Прогрессирование метаболических расстройств в группе сравнения можно связать с целым спектром известных сегодня
Таблица 2. Данные инструментальных методов исследования

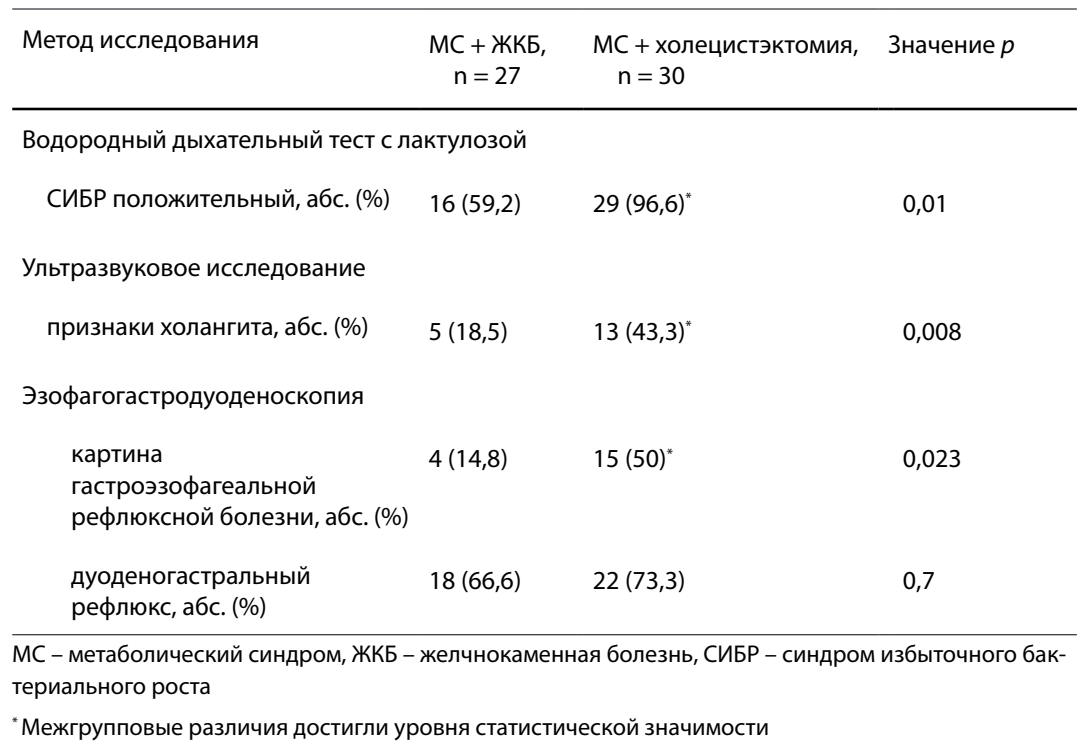

Таблица 3. Характеристика биоптатов печени по Knodell

\begin{tabular}{|c|c|c|c|c|c|}
\hline \multirow[t]{2}{*}{ Параметр } & \multicolumn{2}{|c|}{$\mathrm{MC}+$ ЖКБ, $\mathrm{n}=27$} & \multicolumn{2}{|c|}{$\begin{array}{l}\text { MC + холецистэктомия, } \\
\mathrm{n}=30\end{array}$} & \multirow[t]{2}{*}{ Значение $p$} \\
\hline & степень & абс. & степень & абс. & \\
\hline \multirow{5}{*}{$\begin{array}{l}\text { Индекс } \\
\text { гистологической } \\
\text { активности }\end{array}$} & 0 & 7 & 0 & 0 & \multirow[t]{5}{*}{0,029} \\
\hline & & & & & \\
\hline & 1 & 13 & 1 & 9 & \\
\hline & 2 & 7 & 2 & 13 & \\
\hline & 3 & 0 & 3 & 8 & \\
\hline \multirow[t]{4}{*}{ Индекс фиброза } & 0 & 10 & 0 & 0 & \multirow[t]{4}{*}{0,041} \\
\hline & 1 & 14 & 1 & 11 & \\
\hline & 2 & 3 & 2 & 14 & \\
\hline & 3 & 0 & 3 & 5 & \\
\hline $\begin{array}{l}\text { Жировая дистрофия, } \\
\text { абс. (\%) }\end{array}$ & & $22(81,4 \%)$ & & $30(100 \%)$ & $>0,05$ \\
\hline $\begin{array}{l}\text { Баллонная } \\
\text { дистрофия, абс. (\%) }\end{array}$ & & $8(29 \%)$ & & $22(73 \%)^{*}$ & 0,024 \\
\hline
\end{tabular}

МС - метаболический синдром, ЖКБ - желчнокаменная болезнь

* Межгрупповые различия достигли уровня статистической значимости

причин: прекращением инкреторной функции резецированного желчного пузыря, изменением микробного пейзажа, нарушением метаболизма желчных кислот, повышением энергоемкости пищевых субстратов и синтеза короткоцепочечных желчных кислот, повышением проницаемости 
кишечника, эндотоксемией, нарушением инкреторной функции энтероцитов, развитием депрессивных расстройств и нарушением пищевого поведения.

Инкреторная функция желчного пузыря представлена синтезом К-клетками холецистокинина и D1-холангиоцитами фактора роста фибробластов (FGF-15/19). Нарушение суточного ритма синтеза последнего со значительным падением в послеполуденное время определяет отсутствие соответствующих эффектов - гипогликемического, гиполипидемического, разрешения инсулинорезистентности и контроля синтеза желчных кислот [7].

Снижение концентрации холецистокинина приводит к дискоординации гастродуоденального сегмента и в результате к развитию СИБР в тонкой кишке. Статистически значимая регистрация большего числа гастроэзофагеального рефлюкса у пациентов группы сравнения, вероятно, обусловлена не только повышенной массой тела и развитием СИБР, но и расстройством моторики эзофагогастродуоденальной зоны. Достоверно более частую регистрацию СИБР в этой группе, кроме вышеизложенного, объясняет наличие болюсной билиарной недостаточности, инсулин- и кортизол-опосредованных нарушений третьей фазы моторного миграционного комплекса в виде постпрандиальной гипокинезии и ретроградной дискинезии тонкой кишки $[7,8]$.

Согласно данным литературы, изменение микробного пейзажа при ожирении и сахарном диабете 2-го типа представлено преобладанием филума Firmicutes, снижением количества Bifidobacterium и основного продуцента бутирата - Faecalibacterium prausnitzii. При патологии билиарных путей дополнительно определяется значительный рост пристеночной микрофлоры двенадцатиперстной кишки, выявляется доминирование гемолитических стафилококков, бактерий семейства Enterobacteriaceae, грибов рода Candida и бактероидов. Увеличение частоты встречаемости генов, кодирующих ферменты метаболизма желчных кислот, что характерно для Firmicutes, способствует раннему гидроксилированию желчных кислот. Снижение содержания вторичных желчных кислот приводит к активации их синтеза из холестерина, однако, как известно, печень не способна производить желчные кислоты в количествах, покрывающих их значительный дефицит [8].

В настоящее время основная «ценность» желчных кислот определяется эффектами их взаимодействия с соответствующими ядерными и мембранными рецепторами. Так, в энтероцитах и гепатоцитах активация фарнезоидного X-рецептора (FXR) блокирует синтез желчных кислот из холестерина посредством инактивации цитохрома C450 (CYP27A1) и увеличивает экспрессию переносчиков желчных кислот, что способствует их энтерогепатической циркуляции. Взаимодействие желчных кислот с FXR L-клеток кишечника вызывает снижение экспрессии проглюкагона и глюкагоноподобного пептида-1 (ГПП-1), регулирующих чувство насыщения [5]. Эффекты активации TGR5 (мембранного рецептора желчных кислот) наиболее активно изучаются, и согласно известным механизмам влияния TGR5 желчные кислоты представляются регуляторами углеводного и основного обменов, блокаторами воспаления в ткани печени, эндотелии и жировой ткани, регуляторами функции щитовидной железы на периферии [9].

Известно, что изменение микробного пейзажа приводит к ингибированию АМРК (аденозин-монофосфат-активированной протеинкиназы), что ведет к снижению экскреции инсулина, гипергликемии, блокированию кетогенеза и $\beta$-окисления жирных кислот, активации липогенеза и синтеза холестерина. Микробиота кишечника также способна блокировать экспрессию в жировой ткани FIAL (4-ангиопоэтинподобный антагонист активности липопротеинлипазы), что приводит к активации последней и накоплению триацилглицеридов в адипоцитах.

На фоне СИБР, в связи с усилением процессов сбраживания, отмечается значительное увеличение синтеза короткоцепочечных желчных кислот и изменение их нормального профиля. Биологическая значимость короткоцепочечных желчных кислот опосредована взаимодействием со специфическими рецепторами к жирным кислотам FFAR2 и FFAR3 (англ. free fatty acid receptors), повышением энергоемкости пищевого субстрата, регуляцией синтеза антимикробных пептидов, регуляцией проницаемости тонкой кишки и синтеза холестерина и глюкозы. Стимуляция FFAR2 и FFAR3 приводит к активации липогенеза, ингибированию липолиза и уменьшению расхода энергии. FFAR3 также регулируют перистальтику кишечника и насыщение через ГПП-1 и экспрессию пептида-ҮҮ [10]. Расстройство пищевого поведения принято связывать и с активацией Toll-подобных рецепторов энтероцитов, что приводит к инициации иммунного ответа, повышению проницаемости кишечного и гематоэнцефалического барьеров, 
активации гипоталамо-гипофизарно-надпочечниковой оси, гиперпродукции кортизола и нарушению метаболизма серотонина, а также к нарушению серотонинового и норадреналинового пути регуляции лимбической системы [11]. Увеличение энергетической емкости пищевых субстратов сопряжено с повышенной проницаемостью тонкой кишки для жиров и углеводов, избыточным синтезом короткоцепочечных желчных кислот, преобладанием флоры с генетически детерминированными сахаролитическими свойствами.

Достоверно более частая регистрация диареи в группе оперированных пациентов объяснима секреторным, осмолярным и хологенным компонентами, гипермоторной дисфункцией толстой кишки в рамках синдрома раздраженной кишки в ассоциации с СИБР.

Цитолитический синдром, определяемый с достоверным преимуществом у людей после холецистэктомии, обусловлен повышением концентрации липополисахаридов и иных паттернов кишечных микроорганизмов в кровотоке. Повышение концентрации провоспалительных цитокинов, снижение активности Akt (фосфатидилинозитол-3-киназа) под влиянием дефицита лиганда к TGR5, что индуцирует проапоптотические члены семейства Bcl-2 в гепатоцитах, а также снижение содержания метионина и других составляющих антиоксидантной системы на фоне истощения запасов последних приводят к массивному липоапоптозу гепатоцитов [12]. Некроз гепатоцитов обусловлен токсическим влиянием метаболитов микробиоты, ишемическими сосудистыми реакциями в виде микротромбозов.

Явления холангита рефлюксного характера ассоциированы по данным проведенных ранее многочисленных исследований с выраженной лимфогистиоцитарной инфильтрацией, развитием лобулярного гепатита и сосудистых нарушений в виде расширения синусоидов, полнокровия центральных и портальных сосудов.

Влияние эндотоксемии на развитие фиброза обусловлено индукцией фибропластического фенотипа липоцитов, гепатоцитов, эндотелиоцитов и холангиоцитов. Фибробластами и клетками Купфера также осуществляется синтез внеклеточного матрикса. Наличие генотипа быстрого фиброза (PNPLA3, I148M, мРНК-10b и др.), повышение концентрации воспалительных промоутеров фиброгенеза, цитокинов (лептина, фактора некроза опухоли- $\beta$, интерферона- $\gamma)$, факторов роста (инсулиноподобного, эпидермального, фактора роста гепатоцитов), постоянная активация синтезирующих межклеточный матрикс клеток с одновременным снижением скорости их апоптоза и истощение резервов ингибиторов тканевых металлопротеиназ способствуют увеличению скорости фиброза [13].

Ассоциация прогрессирования фибротических изменений печени с синдромом хронической диареи обусловлена хронической потерей желчных кислот и повышением проницаемости кишечника для липополисахаридов $[14,15]$. Клинические проявления постхолецистэктомического синдрома ассоциированы с дальнейшим развитием фиброза печени, вероятно, ввиду более выраженных моторных расстройств верхних отделов желудочно-кишечного тракта у данной группы пациентов вследствие развития панкреатита и более раннего истощения $\beta$-клеток поджелудочной железы. Жировая дистрофия печени чаще наблюдалась у пациентов группы сравнения, но статистически значимых различий в показателях не достигнуто. Баллонная дегенерация гепатоцитов, отмечаемая со статистически значимо большей частотой в группе пациенток после холецистэктомии, характерна для неалкогольного стеатогепатита, а ее наличие в основной группе, предположительно, обусловлено сосудистыми расстройствами на фоне метаболического синдрома, перенесенными токсическими или иными поражениями печени, выявление которых не входило в задачи настоящего исследования.

Взаимосвязь длительности постхолецистэктомического периода с ростом уровня гликемии и холестерина, а также степенью фиброза определяется прогрессирующим негативным изменением микробного пейзажа тонкой кишки, развитием эндотоксикоза, что приводит к «накопительному эффекту» и развертыванию рецидивирующих и взаимоподдерживающих каскадов окислительного и нитрозативного стресса.

Сосудистый компонент поражения печени определяется в виде расширения портальных трактов и полнокровия синусоидов. Замедление оттока регистрируется и при доплерографии печеночных вен в виде снижения скорости кавального кровотока и «портализации» доплеровской кривой. В настоящий момент подобные изменения кровотока связываются с повышением плотности печеночной ткани на фоне прогрессирования жировой инфильтрации гепатоцитов.

Сосудистый эпителий синусоидов на фоне воздействия окислительного и нитрозативного стресса с последующим развитием апоптоза и формированием «базальной мембраны» претерпевает трансдифференцировку в $\mathrm{CD} 34^{+}-$ 
эндотелий. Сброс нефильтрованной портальной крови в систему центральных вен, расширение объема гипоксического поражения гепатоцитов и фиброзирование перисинусоидальной зоны, синтез медиаторов воспаления и фиброзирования новообразованными эндотелиоцитами способствуют распространению эндотоксемии и окислительного стресса на основное сосудистое русло. Активация ренин-ангиотензин-альдостероновой системы в ткани печени на фоне окислительных расстройств сопровождается изменением концентрации синтезируемого ангиотензиногена. В результате травматизации эндотелия сосудов перегрузкой объемом циркулирующей крови, окисленными липопротеидами, модифицированными белками-переносчиками липидов происходят прогрессирование эндотелиальной дисфункции и запуск атерогенного каскада. Одновременно модификация резистивных сосудов влечет за собой увеличение жесткости сосудистой стенки, признанной наиболее неблагоприятным прогностическим фактором сосудистых осложнений.

Исходя из сказанного, пациенты в постхолецистэктомическом периоде должны рассматриваться как обладающие потенциальным риском развития сердечно-сосудистой и эндокринологической патологии.

Таким образом, результаты настоящего исследования не противоречат упомянутым выше работам других авторов. В качестве положительных сторон нашего исследования отметим: оно проведено на узкой (по гендерному, возрастному и метаболическому критериям) выборке, НАЖБП и неалкогольный стеатогепатит верифицированы как посредством сонографии, так и по результатам биопсии печени. К отрицательным моментам можно отнести небольшую выборку и ретроспективность, что, возможно, не позволило учесть

\section{Конфликт интересов}

Авторы заявляют об отсутствии конфликта интересов.

\section{Финансирование}

Работа проведена без привлечения дополнительного финансирования со стороны третьих лиц. некоторые дополнительные факторы влияния на течение метаболического синдрома и НАЖБП. Однако ранее проведенные исследования с корректировкой соответствующих данных показали незначительное влияние данных факторов на течение изучаемой патологии.

\section{Выводы}

1. Холецистэктомия является предиктором развития неспецифического гепатита.

2. Регистрация биохимической активности неалкогольного стеатогепатита в постхолецистэктомическом периоде ассоциирована с СИБР в тонкой кишке $(\mathrm{p}=0,026)$, ультразвуковыми признаками холангита $(\mathrm{p}=0,041)$ и синдромом диареи $(\mathrm{p}=0,027)$.

3. У пациентов с метаболическим синдромом в постхолецистэктомическом периоде отмечается более раннее выявление фиброза печени относительно естественного течения НАЖБП (средняя длительность постхолецистэктомического периода для F1 составила 5,3 1,9, для $\mathrm{F} 2-7,3 \pm 1,6$ года, $\mathrm{p}=0,32$; для сравнения: по данным клиники Мейо, средняя длительность течения НАЖБП до формирования F1 - 7 лет). Фибротические изменения статистически значимо чаще регистрируются в сочетании с синдромом хронической диареи $(\mathrm{p}=0,034)$ и клиническими проявлениями постхолецистэктомического синдрома в анамнезе $(\mathrm{p}=0,044)$. Выявлена прямая сильная корреляционная связь между степенью тяжести фибротических изменений и длительностью постхолецистэктомического периода $(\mathrm{r}=0,77$; $\mathrm{p}=0,047)$.

4. Холецистэктомия в молодом возрасте выступает предиктором прогрессирования метаболических расстройств у женщин с метаболическим синдромом. (๕)

\section{Литература / References}

1. Shen C, Wu X, Xu C, Yu C, Chen P, Li Y. Association of cholecystectomy with metabolic syndrome in a Chinese population. PLoS One. 2014;9(2):e88189. doi: 10.1371/journal. pone.0088189.

2. Kwak MS, Kim D, Chung GE, Kim W, Kim YJ, Yoon $\mathrm{JH}$. Cholecystectomy is independently associated with nonalcoholic fatty liver disease in an Asian population. World J Gastroenterol. 2015;21(20):6287-95. doi: 10.3748/wjg. v21.i20.6287.

3. Wang HG, Wang LZ, Fu HJ, Shen P, Huang XD, Zhang FM, Xie R, Yang XZ, Ji GZ. Cholecystectomy does not significantly increase the risk of fatty liver disease. World J Gastroenterol. 2015;21(12):3614-8. doi: 10.3748/wjg.v21. i12.3614.

4. Ahmed F, Baloch Q, Memon ZA, Ali I. An observational study on the association of nonalcoholic fatty liver disease and metabolic syndrome with gall stone disease requiring cholecystectomy. Ann Med Surg (Lond). 2017;17:7-13. doi: 10.1016/j.amsu.2017.03.015.

5. Cortés V, Quezada N, Uribe S, Arrese M, Nervi F. Effect of cholecystectomy on hepatic fat accumulation and insulin resistance in non-obese Hispanic patients: a pilot study. Lipids Health Dis. 2017;16(1):129. doi: 10.1186/s12944-017-0525-3.
6. Ramos-De la Medina A, Remes-Troche JM, Roesch-Dietlen FB, Pérez-Morales AG, Martinez S, Cid-Juarez S. Routine liver biopsy to screen for nonalcoholic fatty liver disease (NAFLD) during cholecystectomy for gallstone disease: is it justified? J Gastrointest Surg. 2008;12(12):2097-102. doi: 10.1007/s11605-008-0704-7.

7. Loria P, Lonardo A, Lombardini S, Carulli L, Verrone A, Ganazzi D, Rudilosso A, D'Amico R, Bertolotti M, Carulli N. Gallstone disease in non-alcoholic fatty liver: prevalence and associated factors. J Gastroenterol Hepatol. 2005;20(8):1176-84. doi: 10.1111/j.14401746.2005.03924.x. 
8. Turnbaugh PJ, Hamady M, Yatsunenko T, Cantarel BL, Duncan A, Ley RE, Sogin ML, Jones WJ, Roe BA, Affourtit JP, Egholm M, Henrissat B, Heath AC, Knight R, Gordon Jl. A core gut microbiome in obese and lean twins. Nature. 2009;457(7228):480-4. doi: 10.1038/nature07540.

9. Pattni SS, Brydon WG, Dew T, Walters JR. Fibroblast growth factor 19 and 7a-hydroxy-4-cholesten-3-one in the diagnosis of patients with possible bile acid diarrhea. Clin Transl Gastroenterol. 2012;3:e18. doi: 10.1038/ctg.2012.10.

10. Julio-Pieper M, Bravo JA, Aliaga E, Gotteland M. Review article: intestinal barrier dysfunction and central nervous system disorders - a controversial association. Aliment Pharmacol Ther. 2014;40(10):1187-201. doi: 10.1111/ apt.12950.
11. Teixeira TF, Souza NC, Chiarello PG, Franceschini SC, Bressan J, Ferreira CL, Peluzio Mdo C. Intestinal permeability parameters in obese patients are correlated with metabolic syndrome risk factors. Clin Nutr. 2012;31(5):735-40. doi: 10.1016/j. clnu.2012.02.009.

12. Berr F, Kullak-Ublick GA, Paumgartner G, Münzing W, Hylemon PB. 7 alpha-dehydroxylating bacteria enhance deoxycholic acid input and cholesterol saturation of bile in patients with gallstones. Gastroenterology. 1996;111(6):1611-20.

13. Guo C, Chen WD, Wang YD. TGR5, not only a metabolic regulator. Front Physiol. 2016;7:646. doi: 10.3389/fphys.2016.00646.

14. Trabelsi MS, Daoudi M, Prawitt J, Ducastel S, Touche V, Sayin SI, Perino A, Brighton CA,
Sebti Y, Kluza J, Briand O, Dehondt H, Vallez E, Dorchies E, Baud G, Spinelli V, Hennuyer N, Caron S, Bantubungi K, Caiazzo R, Reimann F, Marchetti P, Lefebvre P, Bäckhed F, Gribble FM, Schoonjans K, Pattou F, Tailleux A, Staels B, Lestavel $S$. Farnesoid $X$ receptor inhibits glucagon-like peptide-1 production by enteroendocrine L cells. Nat Commun. 2015;6:7629. doi: 10.1038/ncomms8629.

15. Cani PD, Amar J, Iglesias MA, Poggi M, Knauf C, Bastelica D, Neyrinck AM, Fava F, Tuohy KM, Chabo C, Waget A, Delmée E, Cousin B, Sulpice T, Chamontin B, Ferrières J, Tanti JF, Gibson GR, Casteilla L, Delzenne NM, Alessi MC, Burcelin R. Metabolic endotoxemia initiates obesity and insulin resistance. Diabetes. 2007;56(7):1761-72. doi: 10.2337/db06-1491 .

\title{
The influence of cholecystectomy at young age on the course of metabolic syndrome in women
}

\author{
Lebedeva O.V.' • Bueverov A.O. • Bueverova E.L. • Nikitina L.O. ${ }^{2}$
}

Rationale: At present, the metabolic syndrome and pathophysiology of non-alcoholic fatty liver disease, as well as identification of factors that may influence the rate of development of dystrophy and fibrosis in the liver are in the focus of investigators' attention. This study represents an attempt to detail metabolic derangements and liver tissue abnormalities after cholecystectomy in patients with metabolic syndrome at baseline. Aim: To study the influence of cholecystectomy performed at younger age on the course of metabolic syndrome in women. Materials and methods: This was a retrospective analytical study in a sample of 57 female patients with metabolic syndrome (International Diabetes Federation criteria 2005) aged from 18 to 44 years (young age according to the World Health Organization definition). From those, 30 patients with cholelithiasis were included into the control group and $27 \mathrm{pa}-$ tients who had undergone cholecystectomy in this age range were included into the comparison group. We analyzed their past history, results of clinical examination, laboratory tests, abdominal ultrasound examination, esophagogastroduodenoscopy, hydrogen respiration test with lactulose, as well as the results of needle liver biopsy.

\section{Conflicts of Interest}

The authors declare that they have no conflict of interest.
Results: Non-alcoholic steatohepatitis after cholecystectomy was associated with the excessive bacterial growth in the small intestine $(p=0.026)$, ultrasound signs of cholangitis $(p=0.041)$, and diarrhea syndrome $(p=0.027)$. Liver fibrosis was significantly more frequent in association with chronic diarrhea $(p=0.034)$ and past clinical signs of post-cholecystectomy syndrome $(p=0.044)$. There was a strong direct correlation between the grade of fibrosis and the time since cholecystectomy $(r=0.77 ; p=0.047)$. Conclusion: Cholecystectomy performed at young age predicts progression of metabolic abnormalities in women with metabolic syndrome.

Key words: cholelithiasis, metabolic syndrome, cholecystectomy, non-alcoholic fatty liver dystrophy

For citation: Lebedeva OV, Bueverov $A O$, Bueverova EL, Nikitina LO. The influence of cholecystectomy at young age on the course of metabolic syndrome in women. Almanac of Clinical Medicine. 2017;45(5):384-91. doi: 10.18786/20720505-2017-45-5-384-391

Received 29 May 2017; Accepted 1 August 2017
Lebedeva Ol'ga V. - Postgraduate Student, Chair of Medical and Social Expert Assessment and Out-Patient Therapy, Postgraduate Medical Training Faculty ${ }^{1}$

$\triangle$ 2/1-41 Kustanayskaya ul., Moscow, 115580 , Russian Federation. Tel.: +7 (916) 9890595. E-mail: ovgastro@mail.ru

Bueverov Aleksey O. - MD, PhD, Professor, Chair of Medical and Social Expert Assessment and Out-Patient Therapy, Postgraduate Medical Training Faculty ${ }^{1}$

Bueverova Elena L. - MD, PhD, Assistant Professor Chair for Propaedeutics of Internal Diseases, Medical Faculty ${ }^{1}$

Nikitina Liliana O. - MD, PhD, Vice-chancellor for Postgraduate and Complementary Training ${ }^{2}$
I.M. Sechenov First Moscow State Medical University; 8/2 Trubetskaya ul., Moscow, 119991 Russian Federation

${ }^{2}$ National Medical Research Center for Rehabilitation and Curortology; 32 Novyy Arbat ul., Moscow, 121099, Russian Federation 